\title{
Profissional da Informação e a Transformação Digital
}

\author{
Francisco Carlos Paletta ${ }^{1}$, José Antonio Moreiro González ${ }^{2}$ \\ ${ }^{1}$ https://orcid.org/0000-0002-4112-5198, Universidade de São Paulo, Brasil. fcpaletta@ usp.br \\ 2 https://orcid.org/0000-0002-8827-158x, UC3M, Espanha. jamore@bib.uc3m.es
}

Palavras-chave: Profissional da Informação; Transformação Digital; Competência Informacional, Gestão da Informação. Inovação; Empreendedorismo.

\section{Introdução}

O valor estratégico da ciência, da tecnologia e da inovação afirmou-se como inquestionável. Avanços nesses campos funcionam como força motora das mais fundamentais dos países industrializados, respondendo também pela ampliação de sua riqueza. Nos últimos anos, países de industrialização recente, como Cingapura, China e Coréia do Sul, revolucionaram suas economias que se tornaram modernas e espantosamente dinâmicas. Por mais que tenham seguido trilhas particulares, não foi diferente, nos casos citados, o estímulo e difusão da cultura de valorização da informação, do conhecimento e da inovação tecnológica - condição indispensável, para disputar eficazmente melhores posições nos concorridos mercados globais.

Literacia informacional tem constituído, nos últimos anos, novo campo de pesquisa que interessa à educação, à ciência da informação e às ciências cognitivas. O desafio está em inicialmente aprender a utilização básica dos recursos tecnológicos - literacia digital - e a seguir apropriar-se dos mesmos para gerar novos conhecimentos - literacia informacional.

No contexto da literacia informacional, os desafios são múltiplos: a dificuldade das bibliotecas universitárias, com suas coleções caríssimas, em concorrer com acervos digitais; as bibliotecas virtuais e os motores de busca oferecendo informações de forma imediata e a custo zero; a desconstrução do conceito de autor individual e a emergência dos coletivos digitais. Os novos contornos da sociedade em rede têm constituído objeto de estudo e pesquisa para profissionais das mais diversas áreas de atuação, especialmente os profissionais da informação, que lidam com os desafios da gestão da informação nas suas dimensões científica, tecnológica, industrial, mercadológica, estratégica e mais recentemente social, Figura 01.

Figura 1 - Dimensões da Informação Fonte: Autor

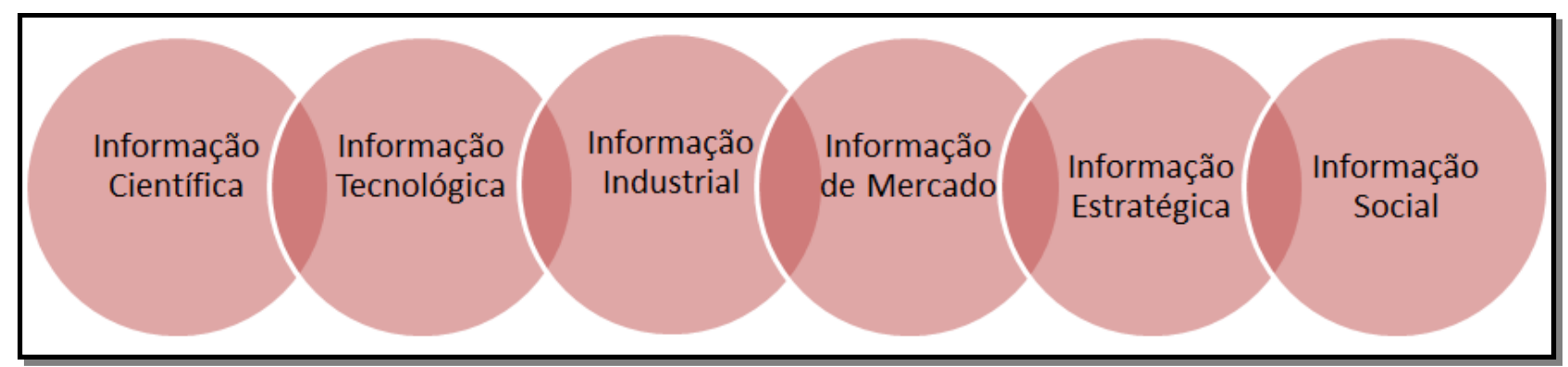

Um dos principais desafios da educação na área da ciência e tecnologia da informação, neste 
novo contexto, onde a tecnologia desempenha papel fundamental e decisivo na organização e gestão da informação bem como na produção de novos conhecimentos, torna-se imperativo desenvolver currículos que proporcionem uma formação alinhada com os desafios do mercado de trabalho global sem deixar de se preocupar com a formação cultural e humanística dos profissionais que atuam na área visando à formação de líderes que possam contribuir ativamente para com o desenvolvimento sustentável e geração de riqueza.

\section{A Organização da Informação, Empreendedorismo, Inovação e o Profissional Bibliotecário}

A incorporação da tecnologia da informação aos modos de produção, a abertura e expansão de exigentes e competitivos mercados e a necessidade urgente das nações emergentes em se adequar à atual conformação global vêm transformando em protagonista um novo binômio: inovação e empreendedorismo.

Para que as organizações possam tirar partido das condições de crescimento possibilitadas atualmente pela globalização, é condição sine qua non o desenvolvimento de instituições fortes e mecanismos modernos que permitam a atualização constante dos modelos de gestão.

A capacidade de gerar conhecimento e transformá-lo em riqueza e desenvolvimento social metas impostergáveis para a própria sobrevivência das organizações - depende da ação de agentes institucionais responsáveis por gerar e aplicar o conhecimento.

É neste contexto que o papel do profissional bibliotecário precisa revisitar suas atribuições e competências redirecionando sua atuação em um cenário cada vez mais competitivo, digital, inovador e criativo, onde a informação ocupa papel estratégico na tomada de decisão e a mediação se faz necessária na busca de excelência operacional e vantagem competitiva.

[...] O profissional de Biblioteconomia desenvolve atividades de organização, tratamento, análise e recuperação de informações em diversos níveis e suportes físicos, por meios manuais e automatizados, com vistas ao atendimento das necessidades informacionais de todos os segmentos da sociedade, ao avanço científico-tecnológicos e ao desenvolvimento social do país. A utilização de novas tecnologias da informação vem exigindo, desse profissional, novas habilidades e provocando mudanças no perfil tradicional. Como resposta à globalização da economia e consequentes transformações mercadológicas e sociais, impõese, cada vez mais, um profissional atuante, com capacidade de oferecer produtos e serviços de informação para esse novo mercado de trabalho. O profissional de Biblioteconomia, que tradicionalmente atua em bibliotecas, encontra novas frentes de trabalho em sistemas e redes de informação de setores públicos, empresariais e industriais, escritórios de assessoria e consultoria, organização de arquivos e de documentação particulares, ensino e pesquisa, podendo atuar como analista da informação, como gestor de serviços de informação e também na área de normalização (CRB-8).

Ciência, Tecnologia e Inovação (CT\&I) são elementos-chave para o crescimento, a competitividade e o desenvolvimento de empresas, indústrias, regiões e países. Também têm importância fundamental na determinação do estilo de desenvolvimento de regiões ou nações e na forma como este afeta no presente e afetará no futuro a qualidade de vida da população em geral e de seus diversos segmentos. Influenciam a educação, a informação, a cultura, os costumes e a sociedade. Também têm papel relevante nos desígnios da política, do desenvolvimento econômico sustentável, distribuição de renda e empreendedorismo. As medidas de CT\&I são importantes porque podem: 
* Alimentar as investigações sobre a natureza e os determinantes dos processos de produção, difusão e uso de conhecimentos científicos, tecnologias e inovações (razão científica);

* Informar a formulação, o acompanhamento e a avaliação de políticas públicas (razão política);

* Informar as estratégias tecnológicas de empresas, assim como as atitudes de trabalhadores, instituições e do público em geral em relação a temas de CT\&I (razão pragmática).

É neste contexto, fomentado pela competitividade, empreendedorismo, criatividade e inovação que o "fazer bibliotecário" precisa encontrar suas novas demandas na mediação, gestão e organização da informação como elemento estratégico de vantagem competitiva das organizações. Ciência, tecnologia e inovação exercem papel fundamental na construção das bases do desenvolvimento econômico sustentável e tem papel relevante na inserção na competitividade global das organizações Figura 2.

Figura 2: Esquema para a Inovação: elementos essenciais para a promoção da competitividade no setor produtivo Fonte: OEA

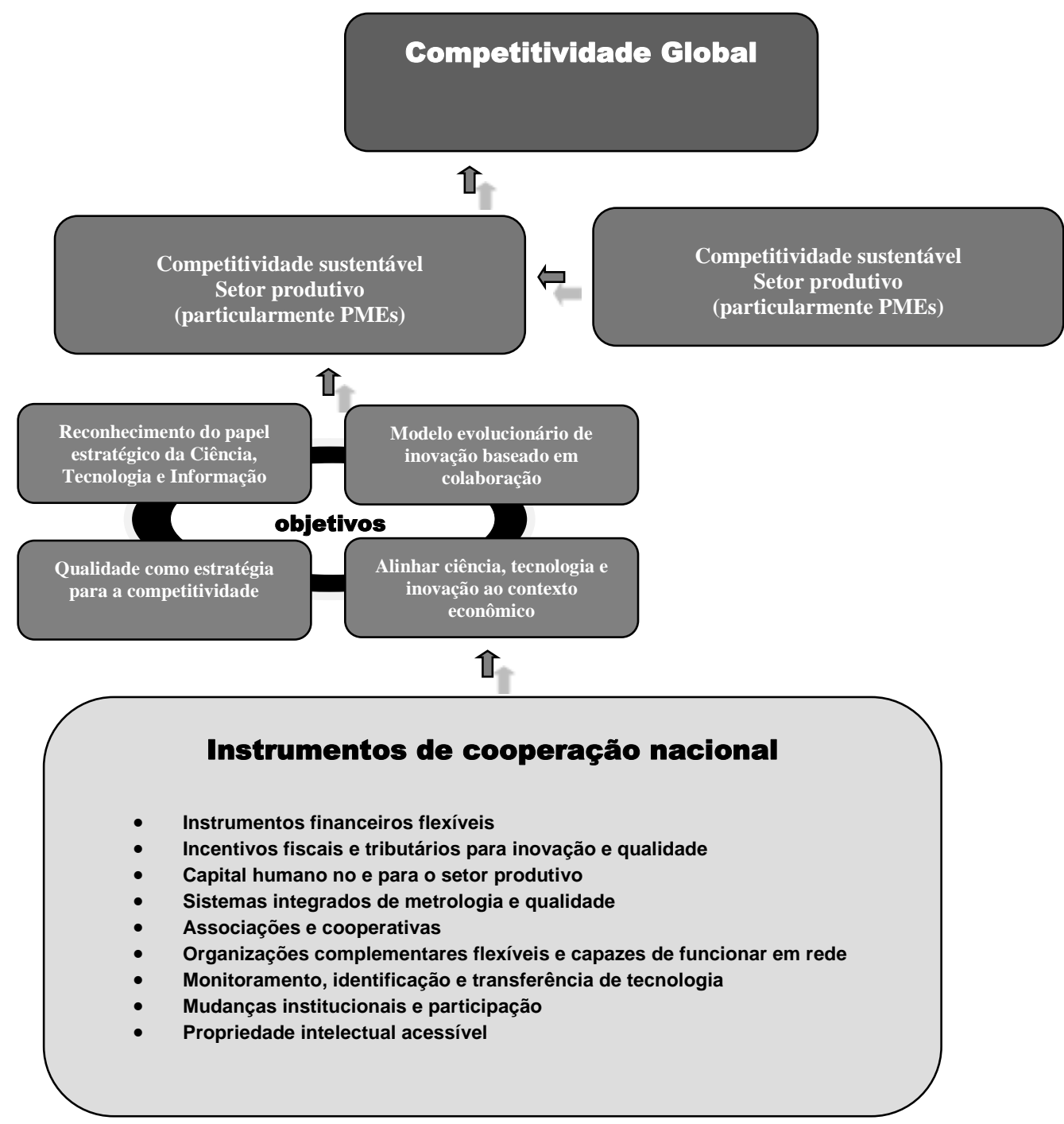

O reconhecimento do papel da ciência, da tecnologia e da inovação na competitividade do setor produtivo deve ser apoiado de diversas maneiras, o que inclui programas de conscientização para as 
diferentes partes envolvidas com o processo de inovação; programas para a difusão dos conceitos de inovação nas comunidades interessadas em atividades produtivas, de modo que a ciência e a tecnologia possam ser mais bem conhecidas e entendidas e, desse modo, melhor utilizadas; capacidade de resposta dos centros de pesquisa em ciência e tecnologia às demandas do setor produtivo; medição de resultados mediante sistemas de intercâmbio, de retroalimentação e monitoração; e apropriação, ou seja, a capacidade de empresas não somente de usar mas também de contribuir para o aperfeiçoamento das tecnologias transferidas (OEA, 2006, p. 33).

Inovação, ciência e tecnologia são conceitos que devem tornar-se parte da nova cultura organizacional do século XXI, de maneira que as empresas, independentemente de tamanho, setor e contexto de atividade produtiva, possam ser capazes de competir na nova ordem mundial. A inovação é uma vantagem competitiva que deve ser desenvolvida e adotada e que não pode estar dissociada de ciência e tecnologia.

\section{Profissional da Informação e a Gestão do Conhecimento}

Num mundo sem barreiras à produção do conhecimento, "mobilidade" passou a ser um conceito chave para todo profissional e para as organizações que competem num mercado cada vez mais globalizado. Mobilidade deve ser entendida não apenas no seu aspecto físico - até porque, num mundo integrado pela tecnologia da informação e da comunicação, a mobilidade está se tornando cada vez mais "virtual" -, mas principalmente no sentido de flexibilidade, de adaptabilidade, de interatividade.

A mobilidade é o conjunto de atributos que permite a um profissional aproveitar novas oportunidades, seja em países estrangeiros ou no próprio local de origem. A mobilidade exige competências que vão além da formação acadêmica tradicional, e a garantia oferecida por padrões internacionais de certificação e acreditação dos diplomas de nível superior.

Esta é uma tendência irreversível que decorre de novas formas de organização da produção em escala planetária, de que são exemplos o outsourcing, ou terceirização dentro das fronteiras nacionais; o offshring, ou terceirização internacional; e a formação de cadeias de suprimento, e de informações e conhecimento. A mobilidade impõe-se pela necessidade de garantir a competitividade dos blocos econômicos regionais, bem como o desenvolvimento local, em resposta aos esforços da competitividade global.

Para alcançar esta mobilidade, o profissional da informação necessita aliar o conhecimento técnico e científico tradicional - elementos básicos da ciência da informação - a habilidades de gestão que o qualificam a assumir responsabilidades no novo ambiente organizacional e a necessidade da disseminação da informação de forma organizada e produtiva.

Num mundo sem barreiras à produção do conhecimento, "mobilidade" passou a ser um conceito chave para todo profissional e para as organizações que competem num mercado cada vez mais globalizado. Mobilidade deve ser entendida não apenas no seu aspecto físico - até porque, num mundo integrado pela tecnologia da informação e da comunicação, a mobilidade está se tornando cada vez mais "virtual" -, mas principalmente no sentido de flexibilidade, de adaptabilidade, de interatividade. 
Esta é uma tendência irreversível que decorre de novas formas de organização da produção em escala planetária, de que são exemplos o outsourcing, ou terceirização dentro das fronteiras nacionais; o offshring, ou terceirização internacional; e a formação de cadeias de suprimento, e de informações e conhecimento. A mobilidade impõe-se pela necessidade de garantir a competitividade dos blocos econômicos regionais, bem como o desenvolvimento local, em resposta aos esforços da competitividade global.

Para alcançar esta mobilidade, o profissional da informação necessita aliar o conhecimento técnico e científico tradicional - elementos básicos da ciência da informação - a habilidades de gestão que o qualificam a assumir responsabilidades no novo ambiente organizacional e a necessidade da disseminação da informação de forma organizada e produtiva.

\section{Resultados}

Novas oportunidades te atuação se apresentam ao profissional da informação e o bibliotecário com suas competências passa a poder atuar em posições estratégicas nas mais variadas áreas do setor produtivo em equipes multidisciplinares como a de data analytics que atua na organização dos dados, e nas equipes de data science que trabalham na construção de algoritmos que compilam dados sobre comportamento dos usuários ao navegar pela Web de Dados.

As organizações na sociedade em rede precisam garantir a gestão e controle de seus destinos digitais e a organização da informação ocupa papel relevante neste cenário ampliando as oportunidades de trabalho para o profissional bibliotecário que tem a possibilidade de atuar com suas competências e habilidades nas mais variadas áreas do setor produtivo. O uso das tecnologias da informação permite ao bibliotecário atuar em novas áreas como o levantamento de informações de Big Data - como é chamado o fluxo de informações geradas, armazenadas e analisadas a partir do tráfego na internet.

Deixar de ser coadjuvante e atuar como protagonista da ruptura digital é o principal desafio do novo fazer bibliotecário que devem estar atentos aos principais temas que refletem as mudanças que surgem entre as líderes digitais do futuro:

\footnotetext{
* Romper a linha tênue entre o digital e o físico: inteligência estendida

* Cadeia de suprimento de dados: a informação em circulação e acessível

* O valor da hiper-escala: proporcionando redução de custos

* Aplicativos orientados ao negócio

* Resiliência arquitetada para negócios ininterruptos

* Da força de trabalho à colaboração em massa: a ascensão das empresas sem fronteiras
}

No contexto da Ciência da Informação, Biblioteconomia, Arquivologia, Museologia e áreas afins, há forte demanda por profissionais com competências e habilidades multidisciplinares, sem fronteiras geopolíticas, com diversidade cultural, com forte dependência por inovação e uso das tecnologias. Assim, torna-se fundamental estudar e compreender o projeto político pedagógico praticado pelas universidades nesta área do conhecimento, sua necessidade de atualização com foco no perfil do egresso que esteja preparado para atuar nos setores estratégicos e produtores de desenvolvimento sustentável da sociedade moderna. 
Para os desafios da competitividade internacional, impõe-se o valor estratégico da ciência e do conhecimento. Dentre as questões macro conjunturais apresentadas para as Universidades que preparam esses profissionais da informação, uma que interessa sobremaneira trata da modernização e internacionalização do nosso modelo acadêmico. Não basta mais garantir a boa formação profissional, é preciso desenvolver as novas habilidades exigidas pelos mais diversos campos de trabalho global.

O atual ambiente de informação está em constante mutação e cada vez mais dependente da hiperconexão das coisas. A busca, acesso, apropriação, e uso da informação de valor é o principal elemento indutor de vantagem competitiva nas organizações. Segundo o Relatório Trend Reports IFLA (2018), identifica-se cinco tendências que irão desempenhar um papel fundamental na formação do nosso futuro ecossistema de informações:

\footnotetext{
* As novas tecnologias irão definir quem tem e quem não tem acesso à informação

* A formação online irá democratizar e romper com a aprendizagem tradicional

* As fronteiras da privacidade e da proteção de dados serão redefinidas

* As sociedades híper-conectadas irão dar ouvidos e poder a novas vozes e grupos

* A economia da informação global será transformada pelas novas tecnologias
}

Um dos principais desafios da educação na área da Ciência da Informação, é o desenvolvimento de currículos que proporcionem uma formação alinhada com os desafios do mercado global, sem deixar de se preocupar com a formação cultural e humanística dos profissionais que atuam na área, em um contexto onde a tecnologia desempenha papel fundamental na gestão da informação e produção de conhecimento fazendo uso de modernos recursos computacionais que permitam a reprodução de ambiente de pesquisa, desenvolvimento e produção que permita vivenciar a realidade competitiva em que as organizações estão inseridas.

\section{Referências}

CRB-8. (2019). O Profissional: Carreira. Sistema CFB / CRB. Disponível em: <http://www.crb8.org.br/carreira.php>. Acesso em: 20 jan. 2019.

OEA. (2006). Ciência, tecnologia, engenharia e inovação para o desenvolvimento: uma visão para as Américas no século XXI. 2006. Disponível em: http://www.oas.org/pt/default.asp. Acesso em: 19 jan. 2018.

TRENDREPORT. (2018). Retrieved January 10, 2019, from https://trends.ifla.org/

AGRADECIMENTO PROCESSO FAPESP: 19/02595-8 